\title{
A Review of Some Recent Breakthroughs in Medical Textiles Research
}

\author{
Gokarneshan N* and Velumani K \\ Department of Textile Technology, Park College of engineering and technology, Coimbatore, Tamil Nadu, India
}

Submission: December 14, 2017; Published: January 26, 2018

*Corresponding author: Department of Textile Technology, Park College of engineering and technology, Coimbatore, India, Email: advaitcbe@rediffmail.com

\begin{abstract}
The recent years has witnessed revolutionary breakthroughs in the area of medical textiles. Some significant contributions have been reviewed in this article. A novel multi layered knitted structure with the coating of the nano fibrous web has been developed for using as aesophaegal prosthesis. This has been achieved through knitting of polyglycolic acid braided yarn into tubular form and coating polycaprolactanenano fibres on the surface. Drug loaded antimicrobial silk suture have been developed for use in both wound closure and wound healing with the object of preventing infections at the surgical area. The material has been found to have satisfactory suture properties. A breathable woven surgical gown with antimicrobial and liquid repellent properties has been developed by finishing with nanoparticles of silver and fluorocarbon using pad-dry-cure method. The coating parameters have been optimized suitably. Cellulosic, polyester-cotton and tencel fabrics as well as PES/PU/ PES laminate have been characterized for use in medical applications, before and after frequent washing and sterilization. Viscose fabrics have been modified to enhance the attraction for nano metal oxides, namely aluminium oxide, zinc oxide or titanium oxide, to impart antimicrobial activity against two species of bacterium. Also the wash durability of the fabrics has been determined. These researches point to better health care strategies.
\end{abstract}

Keywords: Esophaegal prosthesis; Knit structure; Antimicrobial silk suture; Surgical gowns; Barrier textiles; Antimicrobial activity; Nano metal oxides

\section{Introduction}

Considerable developments have taken place over the past decade in the development of medical textiles and these have paved the way towards toward better health managementsystems. Tubular knitted fabrics have been used as a basic structure for making the vascular grafts. The polyester single jersey tubular knitted fabric has been embedded into polycaprolactane composite structure to make a vascular graft [1]. These results showed that this vascular prototype has good mechanical properties due to the knitted structure. Sutures are natural or synthetic materials available in monofilament, multifilament, twisted and braided forms, used widely in wound closure, ligates injured blood vessels and to draw tissues together [2,3]. They are classified into absorbable and non-absorbable category and attached with a metallic needle at one of the fibrous ends. The most important properties of suture materials are physical, mechanical, handling, biological and biodegradation properties. All these properties are interrelated [3,4]. In recent years, attention towards functional finishing of medical textiles such as blood repellent, antimicrobial, and antistatic has increased due to the risk of dangerous microbes development on these fabrics when they come in contact with biological fluids such as blood, sweat etc [5]. Sterile barrier can be defined as a material located between sterile and contaminated areas, with the purpose of preventing microorganisms to penetrate through the material. To obtain a satisfactory microbial barrier system, there are three criteria, viz., enable sterilization, provide a barrier for microorganisms and maintain sterility [6,7]. Textiles can provide a suitable substrate to grow microorganisms especially at appropriate humidity at appropriate and temperature in contact with human body. Recently, increasing public concern about hygiene has been driving many investigations on antimicrobial agents for textiles. These agents are used to prevent serious undesirable effects on textile materials, such as degradation of colouring, staining and deterioration of fibres, formation of unpleasant odour as well as increase of potential health risks [8-10]. A proposal of hygienic living standard by controlling the microorganisms is necessary. Researchers have focussed on the antibacterial and antifungal modifications of textiles by application of inorganic nanotechnology [11-15].

\section{Knitted esophagus prosthesis}

Weft knitting is an age old technology of fabric formation which enables yarn to form loop structure across the fabric width using a set of needles. Owing to their outstanding extensible properties, the weft knitted fabrics are nowadays found a wide 
range of applications. The interloping yarns in the fabric permit the knitted structures to have greater circumferential properties in weft direction as compared to longitudinal direction. Also, these structures have a porous structure that makes them useful for medical and regenerative treatments.

Polyester/spandex tubular weft knit fabric have been used to reinforce a three layer vascular graft [16]. The radial mechanical property of the developed multi layer structure has been assessed and it has been reported that the radial tensile property of the vascular grafts has improved with the use of knitted fabric. Such investigations approve that the use of weft knitted fabrics can enhance the mechanical properties of the tubular prosthesis and vascular prototypes.

Esophagus is a tubular shaped muscular/mucosal tissue that connects the mouth and throat to the stomach. The researchers have shown that there is a non linear and exponential relationship between force and elongation of the esophagus tissue [17]. The mechanical properties of the native esophagus tissue including the axial and circumferential strengths and strains have been measured at $2.19 \mathrm{MPa}, 1.41 \mathrm{MPa}, 70 \%$ and $82.5 \%$ respectively [18].

Some researchers have focused on providing the self expanding metallic and plastic stents, however, the application of metallic stents in benign esophagal strictures is limited due to high risks and problems, such as stent displacement, forming the new strictures, fistula, and hyper plastic reaction of the tissue in the long term $[19,20]$. Knitted textile structures are used as biodegradable stents for treatment of the esophagal disorders. A novel biodegradable knitted poly-l-lactic acid stent has been developed for use in the benign esophageal strictures. This is a novel method for developing the textile based biodegradable stents. However, the mechanipcal properties of this stent haven't been measured for long term applications. This stent also has a significantly open stricture that makes it impossible for use as a tissue engineering scaffold considering the proper conditions the proper conditions for cell growth and proliferation. Hoogencamp et al. have developed a hybrid seamless tubular structure as esophageal prosthesis [21]. They have knitted the PCL yarns into plain sheet structures and then coated the knitted structure by collagen polymer. However, they used the silk knots for making the tubular shape of PCL knitted sheets by surrounding knitted fabrics around a mandrel. These sutured points may be torn due to mechanical loadings during its application and may create leakage sites. The polyester knitted prosthesis have also been effectively used for treatment of the esophageal disorder in a $\operatorname{dog}[22]$.

As stated above, most of the previous works are focused on the use of potential of weft knitted fabrics for making the biodegradable stents and prosthesis. However, these structures have mechanical and morphological limitations [23,24]. A novel biodegradable tubular hybrid structure has been developed that can provide the mechanical properties of the native esophaegal tissue and also introduce a good surface morphology for further cell growth and proliferation during the implementation period. This multi-layer structure is consists of the PCL polymer and an additional layer of gelatin coating. The biodegradable nature of the applied polymers and yarns eliminates the need of further surgeries for removing the prosthesis and also will expose the different functional groups (such as carboxyl groups) to cells. In fact, the use of PGA and PCL as knitted structure and nanofibrous coating leads to a balance in degradation during implantation in the body. This issue is overcome with hydrophilic property of PGA against low contact surface of filament yarn in comparison with hydrophobic property of PCL against high contact surface of nano fibres.

A multi-layer tubular structure has been developed by knitting and electrospinning of the biodegradable PGA yarn and PCL polymer for its use as a substitute for esophaegal diseased tissue. Studies on mechanical properties show that the developed structure has stress and strain values close to real esophagus tissue in both directions. Investigating the effect of stitch density on the mechanical properties of the knitted structures shows that the increase in stitch density has led to increase in axial stress [25]. However, this increase causes a decrease in circumferential stress of the tubular prosthesis from a certain point. Thus, the stitch density value must be set at an optimum value to have good mechanical properties in both directions. The surface roughness measurements for PCL nano fibres coated with gelatin shows that the coating of gelatin has led to increase in surface roughness of the esophaegal prosthesis by $15 \%$ than uncovered structure. Coating the gelatin has also retained the porosity of the tubular structures. In vitro tests demonstrated that three layer micro-nano tubular structure has a controlled degradation in the presence of PBS solution. Results show that the multilayer tubular knitted prosthesis can be used as a biodegradable candidate for substituting the diseased esophaegal tissues and can supply required mechanical properties, surface functionality groups, and proper surface profile for further cell growth and proliferation.

\section{Herbally treated antimicrobial silk suture}

Sutures are found to be a major cause for surgical site infections, occurring within 30 days after a surgical operation (or within one year if an implant is left in place after procedure) which affects either the incision or deep tissues at the operation site [26]. Suture, being a foreign material in surgical wounds enhances the susceptibility of surrounding tissues of wound to infections [27]. Bacteria present in the surgical wound not only contaminate the tissues but also the suture material, which leads ineffectiveness in decontaminating the wound [28]. Bacterial attachments and colonization occurs in all suture material and leads to surgical site infections [29]. Implants have non-shedding surface, skin or other bacteria to form an extra cellular matrix (biofilms), protecting the bacteria from host defence factors $[30,31]$. These biofilms bacteria are difficult to treat and they 
are less sensitive to antibiotics and antiseptics. It is necessary to remove the implant, and antibiotic treatment is essential if biofilms infection is formed [32]. In order to overcome this, many antimicrobial sutures were developed by incorporating suitable antibiotics, antiseptics or their combination. Triclosan, commonly used in antimicrobial sutures, was found to have some demerits such as prematurely change of tadpoles into frogs and reduced sperm production in male rats [33]. Silk is a natural biomaterial which consists of fibroin. It helps in cell attachment and proliferation. Silk suture also possesses goo knot tyeing quality $[34,35]$.

Chitosan is considered as one of the most valuable polymers for biomedical and pharmaceutical applications due to its biodegradability, biocompatibility, non toxicity, and anti tumour properties $[15,16]$. Chitosan is a benefit to wound healing because it stimulates haemostasis and accelerates tissue generation [36]. Suture materials are normally coated with silicon or wax was found to create inflammatory and thrombotic response to the tissues [37]. Coating with chitosan prevents inflammation as well as scar formation with and provides antimicrobial property since silk is easily prone to microbial infection [38].

Aqueous extract of Cynodon dactylon (a traditional herb), commonly called as Bermuda grass was evaluated for their antioxidant, anti inflammatory action while its fresh juice has shown the immuno modulatory and DNA protective activity [3941].

The aerial part extract Cynodon dactylon was found to possess alkaloids, phenols, tannins, and flavonoids on preliminary screening. An antibacterial effect and wound healing property of the grass was investigated by many researchers [42-46].

Efforts have been taken to develop an antimicrobial silk suture preventing surgical site infections by using natural materials having rich medicinal values, which includes biomaterials and medicinal plants [46].

In this study silk has been used as suture material and fabricated using a circular braiding machine. The silk suture is coated with chitosan (a biopolymer) and incorporated with Cynodon dactylon (a natural drug) [47]. The coated suture is found to have good properties. In order to obtain optimum antimicrobial efficacy, response surface optimization process using Box-Behnken experimental design is applied. It is found that $1.7 \%$ chitosan and $7 \%$ drug at $60 \mathrm{oC}$ has optimum antimicrobial efficacy with effective bacterial reduction against S.Aureus and $E$. Coli, when subjected to antimicrobial study.

\section{Breathable surgical gowns}

Surgical gowns and surgical masks are important textile products among different kinds of medical textile products, and protect surgeons from hazardous viruses such as Hepatitis B, HIV, etc [48-50]. These microbes, normally present in the patient's blood, are much smaller than the pore size of the fabric and thus can easily make contact with the skin of surgeons. In order to protect the surgeons from the penetration of these viruses, spun laced, melt blown, and spun bonded/melt blown/spun bonded non woven fabrics are used as surgical gowns [51].

But, these non woven fabrics are not widely used in indian hospitals due to their limitations such as high cost, low blood barrier effect and not reusable. Mostly cotton and polyester/ cotton blended woven fabrics are widely used for developing surgical gowns [49]. These woven fabrics have many benefits, such as low cost, stability against wash/reusability, reduced medical waste, good air permeability and good moisture transport which are highly suitable for surgical gowns [52]. In order to get functional properties surgical gowns are provided with liquid repellent and antimicrobial finishing (dual finish). Several studies have been carried out on developing the above mentioned fabric by finishing the fabrics with liquid repellent and antimicrobial agents. Attempts have been taken to develop the antimicrobial and liquid repellent cotton nonwoven fabrics by treating chitosan and fluoro polymers [53]. It has been found that dual finished has low antimicrobial and air permeability values. Whereas, cetyltrimethyl ammonium bromide and fluoroaklyl acrylic copolymer have been used for developing a dual finished fabric [54]. The finished fabric showed better liquid repellency, however moisture vapour permeability of the finished fabric was affected. In another study, neem extracts and fluorocarbon have been applied on the fabric surface and the finished fabric exhibited low antimicrobial activity due to presence of fluorocarbon on the surface of the fabric [55]. In order to improve the antimicrobial property, finishes have been imparted on cellulose fibre surface by applying nano silver and fluorocarbon [56]. The finished fabric exhibited good antibacterial and repellent properties; nevertheless air and water vapour permeability of the fabrics were affected. On the other hand, fluorocarbon and CTAB have been applied on the surface of polypropylene and polyethylene fabrics. The finished fabric showed good antimicrobial property, however the liquid repellent nature of the fabric was reduced due to cationic nature of CTAB. It has been observed from the reported literature that developing a dual finished fabric with good air and water permeability is a challenging work. The protective surgical gowns should be given a dual finish without affecting the breathability and comfort of the fabrics. While developing a dual finished fabric, uniform dispersion of chemicals on fabric surface is an important requirement for developing a good quality antimicrobial and liquid barrier fabric. From the published literatures it has been observed that the fabric finished with nano chemicals provide an excellent functional performance, such as oil and water and oil repellency, stain proof, antibacterial, antistatic, etc. without compromising the breathability of the fabrics $[57,58]$. Hence, nano liquid repellent and nano antibacterial agents have been applied on surgical fabrics which can provide good liquid repellent and antimicrobial characteristics to the fabric along with better breathability. Nano silver and nanofluoro carbon 
have been taken along with a binder and applied on surgical fabric. The concentration of solutions has an influence on the fabric properties, and hence solution concentrations of nano silver, nanofluoro carbon and binder have been considered variables and then optimized using a statistical tool.

Surgical fabric with antimicrobial and liquid repellent (liquid barrier) characteristics have been developed by coating it with nano silver and nanofluoro carbon without affecting its air and moisture vapour permeability. The increase in NS concentration at high level of NFC and binder increases the add-on $\%$ of fabric. In case of repellent property, the increase in NS concentration from $1 \mathrm{~g} / \mathrm{L}$ to $5 \mathrm{~g} / \mathrm{L}$ has no significant change in surface contact angle of fabric. However, the increase in NFC concentration from $10 \mathrm{~g} / \mathrm{L}$ to $70 \mathrm{~g} / \mathrm{L}$ increases the contact angle of fabric from $60 \mathrm{o}$ to 140 o.

In case of air permeability of the fabric, the increase in NS concentration from $1 \mathrm{~g} / \mathrm{L}$ to $5 \mathrm{~g} / \mathrm{L}$ reduces the air permeability of the fabrics. The increase in binder concentration from $10 \mathrm{~g} / \mathrm{L}$ to $15 \mathrm{~g} / \mathrm{L}$ increases the air permeability of fabrics. However, at high level of binder concentration $(20 \mathrm{~g} / \mathrm{L})$, air permeability of fabric is reduced. In case of moisture vapour transfer rate of finished fabric, the increase in NS concentration from $1 \mathrm{~g} / \mathrm{L}$ to $3 \mathrm{~g} / \mathrm{L}$ increases the fabric moisture vapour transfer from $795 \mathrm{~g} /$ $\mathrm{m}^{2} /$ day to $805 \mathrm{~g} / \mathrm{m} 2 /$ day. However, at $5 \mathrm{~g} \mathrm{NS}$, the fabric moisture vapour transfer is reduced from $805 \mathrm{~g} / \mathrm{m} 2 /$ day to $790 \mathrm{~g} / \mathrm{m}^{2} /$ day. Anti-bacterial activity of NS and NFC finished fabric against $E$. Coli reveals that the increase in NS concentration increases the bacterial inhibition zone whereas binder concentration has no effect on antibacterial activity [59]. The same result is also obtained for the fabric tested against the bacterial strain $S$. Aureus. In case of tensile strength of finished fabric the increase in NS and binder concentration increases the tensile strength of the fabric. In case of bending modulus of finished fabric, increase in NS concentration increases the bending modulus of the fabric. The increase in NFC concentration reduces the bending modulus of the fabric. In addition, the increase in binder concentration from $10 \mathrm{~g} / \mathrm{L}$ to $20 \mathrm{~g} / \mathrm{L}$ at low level of NS (1-3g/L) has no significant change on fabric bending modulus. Therefore, bending modulus of fabric is positively influenced by NS particle and not by NFC particles. It has been concluded that the fabric treated with $3 \mathrm{~g} / \mathrm{L}$ of nano silver, $40 \mathrm{~g} / \mathrm{L}$ nano fluorocarbon and $15 \mathrm{~g} / \mathrm{L}$ of binder imparts better antimicrobial and liquid repellent properties without affecting the breathability of the fabrics.

\section{Effect of sterilization and washing on fabrics used for medical applications}

Sterile material, to be used later should be stored immediately after the sterilization process, while the period of storage depends on the type of packaging, transportation, storage and handling conditions. Each sterilized material has its own lifetime, as defined by the time its sterility is maintained. Packaging protects sterilized material against contamination from microorganisms, particles and solutions after sterilization at the same time allowing permeability of air and sterilization medium. The microbial barrier system should provide protection against the penetration of microorganisms and maintain sterility of the products. Textile materials can also be efficient barriers applied in packing of material for sterilization, surgical gowns, cover and masks. Previous testing of microbial barriers was conducted with the goal of determining whether the applied medical textiles (one layer) can provide safe protection against contamination after sterilization, regardless of the fact that they did not meet the standard EN 868-02:2009 and EN ISO 11607-1:2009. It was proved repeatedly used medical textiles could provide a safe microbial barrier against contamination for packaging in sterilization, coincidence the validity term of minimum 3 months, 50 washing and 50 sterilization cycles [60]. Complete research findings of permeability in microbial barrier have been published earlier. Contaminated medical textiles are a potential source of microbes and contribute to the transfer of hospital pathogens by endogenous and indirect contacts $[61,62]$.

It is known that washing causes some changes in fabric characteristics, which can also affect the barrier properties [63]. Efforts have been taken to identify a degree of modification of cellulosic medical textiles proved to be an efficient barrier system, after multiple washing and sterilization cycles. Hence, the characterization of two cellulosic medical textiles and three layer textile laminate PES/PU/PES used for packaging, surgical material in sterilization and in operation theatres have been performed employing surface characterization, change in spectral characteristics and tensile properties. Surface characterization is based on SEM micrographs and zeta potential, which provides an insight of the charge and adsorption characteristics of solid surfaces. Due to possible contamination by cotton dust and due to microbiological cleanness $100 \%$ cotton fabric has not been used.

It is observed that washing and sterilization performed through 50cycles have an impact on tensile, spectral and surface characteristics [64]. Optical properties of tencel are found to be deteriorated due to unadapted washing conditions. Cellulosic fabrics show most prominent changes in all the relevant properties, when compared to laminate.

\section{Modified viscose fabrics with enduring antibacterial activity}

As most textile fabrics would undergo repeated laundering during their life time, the washing durability of nano metal treated fabric is of significant importance. Polycarboxyilc acids are a multifunctional organic molecules with chemical and thermal stability $[65,66]$. Polycarboxylic acids could form ester linkage with hydroxyl groups of cellulosic fabrics at elevated temperature above $160 \mathrm{oC}$. They have also been used to improve the adhesion of the inorganic-organic interface [67].

Permanent viscose fabrics have been prepared by fixation of propionic acid groups at lower temperature (below $100 \mathrm{oC}$ ), as active centres, onto the cellulosic polymer chain. The added carboxylic groups are believed to act as favourable centres for 
some oxides such as titanium dioxide, zinc oxide, or aluminium oxide nano particles. The efficacy of the antimicrobial activity, considering the permanent performance against selected microorganisms onto modified textile, is also evaluated.

FTIR spectra of untreated viscose fabric as well as fabrics pre-treated with 3-bromopropionic acid and then with nano metals show a support for the reaction between the viscose fabrics and 3-bromopropionic acid and then with nano metals shows a support for the reaction between the viscose fabrics and 3-bromopropionic acid [68]. The alkali combining capacity values increase remarkably as the amount of 3-bromopropionic acid is increased during the modification of the viscose fabrics, which supports the reaction between- $\mathrm{OH}$ active group of viscose and bromine halide of 3-bromopropionic acid. It has been found that the introduced carboxylic groups can attract the nano metal oxides from their suspension to the fabrics. It has been found that the viscose fabrics treated with 3-bromopropionic acid are incapable of resisting the growth of the microorganism. A unique ability to stop growth of these microorganisms on the viscose fabric can only be attained when treated with 3-bromopropionic acid followed by after treatment with nano metal oxides. It is also obvious that the ability of nano metal treated viscose fabrics to reduce the microbial growth is in the following order: zinc oxide>aluminium oxide>titanium (IV) oxide. 3-bromopropionic acid has a superior antifungal activity in comparison with its antibacterial activity. The added carboxylic groups to the fabrics is not only acting as attracting groups for the nano metal oxides, but also fixing these nano metal oxides to the fabric. The viscose fabrics treated with 3-bromopropionic acid and nano metal oxides are found able to maintain high antimicrobial activity even after 30 wash cycles.

\section{Conclusion}

Investigations on the tubular knitted fabrics intended for use as esophaegal prosthesis have revealed that its mechanical properties are similar to real esophaegal tissue. Coating of gelatine increases the surface roughness of the PCL nanofibrous web and also retains the porosity of the final structure. Degradation test also shows that the PGA knitted fabric coated with PCL nanofibres and gelatin is degraded in a controlled manner. It can be said that this tubular knitted structure can be considered as a substitute for prosthetic application in different esophaegal diseases after biological investigations. Silk suture material has been analysed for various suture properties such as tensile strength, elongation, knot strength, bending properties and diameter. The suture material is coated with chitosan which is a biopolymer and incorporated with herbal drug Cynodondactylon. Effective bacterial reduction percentage have been found against the bacterial culture considered. Thus, the natural drug loaded suture material would be a better alternative for synthetic drug loaded suture which is found to have some demerits. In the development of breathable woven surgical gown coated with silver nanoparticles and fluorocarbon the critical coating parameters have been optimized. The coating parameters considered are concentrations of nano silver, nanofluoro carbon and binder, which have decisive influence over the fabric properties. The antibacterial activity of the fabric is found to be higher for increased nano silver concentration and lower for increased nanofluorocarbon. Studies on cellulosic, polyester/cotton, tencel fabrics, and polyester, polyurethane, polyester laminate used for medical applications have shown that during washing and sterilization, cellulosic fabrics show prominent changes of all studied properties than that of polyester, polyurethane, polyester laminate. Studies on viscose fabrics pretreated with 3-bromopropionic acid and after treatment with nano metal oxides have revealed an unique ability to stop microorganisms growth on the fabrics. The ability of the nano metal oxide treated viscose fabrics to reduce microbial growth is found in the following order: zinc oxide>aluminium oxide>titanium (IV) oxide. The durability of antimicrobial activity has been tested after thirty wash cycles.

\section{References}

1. Wang FG, Mohammed A, Li C, Ge P, Wang L, et al. (2014) Biomedical material engineering 24: 2127.

2. Adekogbe I, Ghanem A (2005) Biomaterials 26: 7241.

3. Chu C (2002) Textile based biomaterials for surgical applications. Polymeric biomaterials (New York CRC Press), USA, pp. 167.

4. Chaouat M, Le Visage C, Auttisier A, Chaubet F, Letourneur D, et al. (2006) Biomaterials 27: 5539.

5. Virk RK, Ramaswamy GN, Bourham M, Bures BL (2004) Textile Research Journal 74: 1073.

6. Enko MT (2009) Sterile supply packaging (WFHSS-OGSV Basic script).

7. Bojic-Turcic V (1994) Sterilizacija I dezinfeckcija u medicine (Medicinskanaklada and Medicom, Zagreb).

8. Ren X, Kou L, Kocer HB, Zhu C, Worley S, et al. (2008) Colloids Surfaces A: Physiochemical engineering aspects 317: 711.

9. Dastjerdi R, Montazer M, Shahsavan S (2009) Colloids Surfaces A: Physiochemical engineering aspects 345: 202.

10. Dastjerdi R, Mojtahedi M, Shoshtari A, Khosroshahi A (2010) Journal of textile institute 101: 204.

11. Gao Y, Cranston R (2008) Textile research journal 78: 60.

12. El-Sayeed AA, Dorgham SM, Kantouch A (2012) International journal of biology and macromolecules 50: 273.

13. Kantouch A, El-Sayeed AA, Salama M, El-Khair AA, Mowafi S (2013) International journal of biology and macromolecules 62: 603.

14. Mekewi M, El-Sayeed AA, Amin M, Said HI (2012) International journal of biology and macromolecules 50: 1055.

15. Wong Y, Yuen C, Leung M, Ku S, Lam H (2006) Autex research journal 6: 1 .

16. Yang H, Zhu G, Zhang Z, Wang Z, Fang J, et al. (2012) J Biomed Mater Res [B]: Appl Biomater 100B: 342.

17. Gregersen H, Liao D, Fung YC (2008) J Biomech Eng 130: 1.

18. Vanags I, Petersons A, OseV, Ozolanta I, Kasyanov V, et al. (2003) J Biomech 36: 1387.

19. Song HY, Do YS, Han YM, Sung KB, Choi EK, et al. (1994) Radiology 193 689. 
20. Holt AP, Patel M, Ahmed MM (2004) Gastro intest Endosc 60: 1010.

21. Saito Y, Tanaka T, Andoh A, Minematsu H, Hata K, et al. (2007) World J Gastroenterol 13: 3977.

22. Hoogenkamp HR, Koens MJW, Geutjes PJ, Ainoedhofer H, Wanten G, et al. (2014) Tissue Eng[C]: Methods 20: 423.

23. Muste AN, TănaseA, Muste MM, Beteg FL (2014) Acta Vet Brno 83: 243.

24. Javad Y, Dariush S, Amin Z, Seyghlani, Shahnaz R (2017) A novel biodegradable micro-nano tubular knitted structure of PGA braided yarns and PCL nanofibres applicable asesophagus prosthesis. Indian Journal of Fibre \& Textile Research 42: 264-270.

25. Owens CD, Stoessel K (2008) J Hosp Infect 2: 3.

26. Justinger C, Moussavian MR, Schlueter C, Kopp B, Kollmar O, et al. (2009) Surgery 145: 330.

27. Rodeheaver GT, Kurtz LD, Bellamy WT (1983) Arch Surg 118: 322.

28. Rothenburger S, Spangler D, Bhende S, Burkley D (2002) Surg Infect (Larchmt) 3(1): 79.

29. Leaper D, McBain AJ, Kramer A, Assadian O, Sanchez JL, et al. (2010) Ann R Coll Surg England 92: 453.

30. Gomez-Alonso A, Garcia-Criado FJ, Parreno-Manchado FC, GarciaSanchez JE, Garcia-Sanchez E, et al. (2007) J Infect 54: 82.

31. Ming X, Rothenburg S, Yang D (2007) Surg Infect (Larchmt) 8: 201.

32. Brausch JM (2011) Chemosphere 82: 1518.

33. Gupta MK, Khokhar SK, Phillips DM, Sowards LA, Drummy LF, et al. (2007) Langmuir 23(3): 1315.

34. Gurumoorthi BB, Sheela Raj Z, Nachane RP, Radhalakshmi YC, Joseph MA (2013) J Text Assoc 73:(2013)351.

35. Kumar MNVR (2000) Reactive Functional Polym 46: 1.

36. Keong LC, HalimA S (2009) Int J Mol Sci 10: 1300.

37. Hoekstra A, Struszczyk H, Kivekas O (1998) Biomaterials 19: 1467.

38. Altman GH, Diaz F, Jakuba C, Calabro T, Horan RL, et al. (2003) Biomaterials 24(3): 401 .

39. Viju, Thilagavathi G (2002) Fibres Polym 13(6): 82

40. Kumar A, Sawarkar HA, Deshmukh VS, Mishra KK, Singh M, et al. (2011) Int J Herbal Drug Res 1(1): 1.

41. Santhi R, Kalaiselvi K, Annapoorani S (2010) J Pharmacy Res 3(2): 228.

42. Garg VK, Paliwal SK (2011) Int J Pharmacol 7(3): 370.

43. Anand K, Kashyap P, Sawarkar H, Muley B, Pandey A (2011) Int J Herbal Drug Res 1(2): 31.

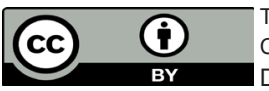

This work is licensed under Creative Commons Attribution 4.0 Licens DOI: 10.19080/CTFTTE.2018.02.555588
44. Suresh K, Deepa P, Harisaranraj R, Vaira A (2008) Ethno Botanical Leaflets 12: 1184.

45. Thakare VM, Chaudhari RY, Patil VR (2011) Int J Phytomedicine 3: 325

46. Dande Payal, Khan Anis Asian (2012) J Pharm Clin Res 5(3): 161

47. Garg Vipin Kumar, Khosa RL, Paliwal SK (2009) Pharmacologyonline 1: 1246 .

48. Virk RK, Ramasamy GN, Bourham M, Bures BL (2004) Textile Research Journal 74.

49. Behera BK, Arora H (2009) Journal of industrial textiles 38: 205.

50. Montazer M, Rangchi F (2009) Textile apparel 2: 128.

51. Huang W, Leonas KK (2000) Textile research journal 70: 774

52. Rutala WA, Weber DJ (2001) Infection contagious hospital Ep 22: 248.

53. Lee S, Jeong SC, Cho G (1999) Textile Research Journal 69: 104

54. Bagherzadeh R, Montazer M, Latifi M, Sheikhzadeh, M, Sattari M (2007) Fibres Polymers 8: 386.

55. Thilagavathi G, Kannian T (2008) Indian journal of fibres and textile research 33: 23.

56. Tomsic B, Simonc B, Lidija BC (2008) Journal Sol-Gel Technology 47: 44.

57. Joshi M, Bhattacharya A, Ali SW (2008) Indian journal of fibre and textile research 33: 304 .

58. Jegatheesan K, Senthilkumar T, Neelakandan R (2017) Indian journal of fibre and textile research 42: 453 .

59. Rogina-Car B, Budimir A, Tuttie V, Katovie D (2014) Cellulose 21: 2101 60. Borkow G, Gabbay (2008) J Med Hypotheses 70: 990.

61. Fijan S, Sc Atar-Turk S (2012) Int Environ Res Public Health 9: 3330.

62. Leonas KK (1998) Am J Infect Control 26: 495.64.

63. Rogina-Car B, Page T, Dekanie T (2016) Impact of washing and sterilization on properties of fabrics used for medical applications. Indian journal of fibres and textile research 41: 426.

64. Bendak A, Raslan W, Salama M (2008) J Natural Fibers 5: 251.

65. Salama M, Bendak A, Moller M (2011) Ind Textila 62: 320.

66. Mao Z \& Yang C Q (2001) J Appl Polym Sci 81: 2142.

67. Huang W, Xing Y, Yu Y, Shang S, Dai J (2011) Appl Surface Sci 257: 4443

68. Atef El-Sayed A, Salama A, Sohad MD, Kantouch A Modification of viscose fabrics to impart permanent antimicrobial activity.

Your next submission with Juniper Publishers will reach you the below assets

- Quality Editorial service

- Swift Peer Review

- Reprints availability

- E-prints Service

- Manuscript Podcast for convenient understanding

- Global attainment for your research

- Manuscript accessibility in different formats

( Pdf, E-pub, Full Text, Audio)

- Unceasing customer service

Track the below URL for one-step submission https://juniperpublishers.com/online-submission.php 